\title{
Effects of Ag Doping on the Thermoelectric Properties and Microstructure of PbSbTe
}

\author{
Tao-Hsing Chen* and Ming-Tai Hong \\ Department of Mechanical Engineering, National Kaohsiung University of Applied Sciences, \\ Kaohisung 807, Taiwan
}

(Received August 31, 2015; accepted February 23, 2016)

Keywords: PbSbTe, Seebeck coefficient, thermoelectric properties, ZT value

In this study, $\mathrm{Pb}_{18} \mathrm{Sb}_{5} \mathrm{Te}_{20}$ is used as a substrate to which different amounts of $\mathrm{Ag}$ are added to form $\mathrm{Ag}_{1-y} \mathrm{~Pb}_{18} \mathrm{Sb}_{5} \mathrm{Te}_{20}(y=0,0.1,0.2,0.3,0.4)$ alloys. All the experiments use vacuum arc melting to produce a series of bulk thermoelectric materials. X-ray diffraction (XRD) analysis and Joint Committee on Powder Diffraction Standards (JCPDS) database are used to confirm the crystal structure of all materials. This study investigates the thermoelectric properties of the alloys using the Seebeck coefficient, thermal conductivity, and resistivity parameters. The addition of Ag enhances the thermoelectric figure of merit (ZT) value of PbSbTe-based thermoelectric materials. Scanning electron microscopy (SEM) was also used to observe the fracture surface of all tested materials.

\section{Introduction}

Thermoelectric materials can be used in the manufacture of thermoelectric heat generators or coolers. These materials can directly convert heat into electricity and power to achieve cooling. Thermoelectric devices have many advantages: (1) they are small and light, (2) they provide reliable local cooling, and (3) they can function under severe vibration or in harsh environments. Their disadvantages are: (1) high manufacturing costs make mass production difficult, (2) the heat transferred from one end of the element to the other has to be removed by a cooling fan and heat sink, and (3) thermoelectric efficiency is only about $5 \%$, which is rather low. It takes about $100 \mathrm{~W}$ of electric power to remove $5 \mathrm{~W}$ of heat. ${ }^{(1,2)}$

A material with good conductive properties generally has a relatively high heat transfer rate, which is a continuing problem in this area of research. In recent years, these semiconductor-based materials have been grown by molecular beam epitaxy (MBE) or chemical vapor deposition (CVD) as multilayered films or so-called superlattice structures. They can be a few nanometers to several tens of nanometers thick, which results in the manifestation of quantum effects. However, the interfaces of multilayered superlattice films enhance the probability of additional lattice-scattering, and this reduces heat conduction. Therefore, thin film thermoelectric materials can be expected to significantly alter the thermoelectric figure of merit $(\mathrm{ZT})$ value of the structure. For example, the $\mathrm{ZT}$ value of the $\mathrm{Bi}_{2} \mathrm{Te}_{3} / \mathrm{Sb}_{2} \mathrm{Te}_{3}$ and $\mathrm{PbTe} / \mathrm{PbSe}$ superlattices can reach more than 2.(3,4)

${ }^{\bar{*}}$ Corresponding author: e-mail: thchen@cc.kuas.edu.tw 
Recently, compounds with a bismuth telluride substrate have been extensively studied and have become among the most important thermoelectric materials ${ }^{(5-7)}$ used at room temperature, and much research has been done on the composition of material, for example: $\mathrm{Bi}_{2} \mathrm{Te}_{3}, \mathrm{Bi}_{2} \mathrm{Te}_{3}-\mathrm{Sb}_{2} \mathrm{Te}_{3}$ and others. ${ }^{(8)}$ The thermoelectric material usually consists of a semiconductor doped with $\mathrm{Sb}$ for P-type and $\mathrm{Se}$ for N-type behavior. Among new thermoelectric materials, ${ }^{\left({ }^{9}\right)} \mathrm{AgPb}_{m} \mathrm{SbTe}_{m+20}$ with a PbTe substrate has a high $\mathrm{ZT}$ value at $700 \mathrm{~K}$; however, excess $\mathrm{Pb}$ significantly reduces the thermal conductivity. The most extensive studies have been carried out on $\mathrm{PbTe}$, which is a medium-temperature material with ZT value of 1 , which can also be used as a heater. ${ }^{(10-12)}$ Some studies ${ }^{(13-16)}$ used different methods to measure $\mathrm{ZT}$ values, and the results are inconsistent. In this study, we use $\mathrm{Pb}_{18} \mathrm{Sb}_{5} \mathrm{Te}_{20}$ as the bulk substrate, which is then doped with $\mathrm{Ag}$ to form $\mathrm{Ag}_{x} \mathrm{~Pb}_{18} \mathrm{Sb}_{5} \mathrm{Te}_{20}(x=0.6-1)$, and we characterize its thermoelectric properties. The doping concentration can affect the power factor and the Fermi level to achieve a maximum $S^{2} \sigma$ value. ${ }^{(17)}$ Therefore, we theorized that Ag doping would improve the Fermi energy level of the bulk material and that this improvement might present a new course for research and development of thermoelectric alloys.

\section{Materials and Experiments}

The experimental work included material preparation, component analysis, microstructure analysis, and thermoelectric property measurement. Powdered lead ( $\mathrm{Pb} 99.99 \%)$, antimony ( $\mathrm{Sb}$ 99.99\%), tellurium ( $\mathrm{Te} 99.99 \%$ ) and silver ( $\mathrm{Ag}$ 99.99\%) were mixed in the desired mole ratio and then compressed into tablets in hydraulic press. The tablets were processed by smelting in a vacuum arc furnace to form a ternary alloy, $\mathrm{Ag}_{x} \mathrm{~Pb}_{18} \mathrm{Sb}_{5} \mathrm{Te}_{20}(x=0.6,0.7,0.8,0.9,1)$. The vacuum arc smelting was repeated three times at $873 \mathrm{~K}$ for $12 \mathrm{~h}$. Before melting, the chamber was pumped to a background pressure lower than $10^{-2}$ Torr. A slow cool-cutting machine was used to cut strips of appropriate size from the resulting ingots. The strips were polished mechanically. Component and microstructural analyses were carried out on the strips, and the Seebeck coefficient was measured. The electrical conductivity and Seebeck coefficient were measured using a four-point direct current and commercial equipment [ZEM-3 (M8)] system. The thermal conductivity was calculated from the equation $k=\alpha C_{\mathrm{p}} \rho$, where $\alpha$ is the thermal diffusivity, $C_{\mathrm{p}}$ is the heat capacity, and $\rho$ is the density. Furthermore, the value of $\alpha$ was measured by the laser flash technique (TC9000, Ulvac-Riko, Tokyo). The results and calculated ZT values were compared with the results of previous studies. The component and microstructure analyses were done by X-ray powder diffraction, and field-emission scanning electron microscopy (FESEM) was used to study the surface structure.

\section{Results and Discussion}

\subsection{X-ray diffraction (XRD) analysis of $\mathrm{Ag}_{x} \mathrm{~Pb}_{18} \mathrm{Sb}_{5} \mathrm{Te}_{20}(x=0.6,0.7,0.8,0.9,1)$}

Figure 1 shows XRD plots of $\mathrm{Ag}_{x} \mathrm{~Pb}_{18} \mathrm{Sb}_{5} \mathrm{Te}_{20}(x=0.6,0.7,0.8,0.9,1)$. Using the Joint Committee on Powder Diffraction Standards (JCPDS) database, we found that the main structure of the alloy crystal was $\beta$-PbTe with a space group of $\mathrm{Fm} 3 \mathrm{~m}$ and a crystal structure comprised two interwoven face-centered cubic (FCC) lattices. 


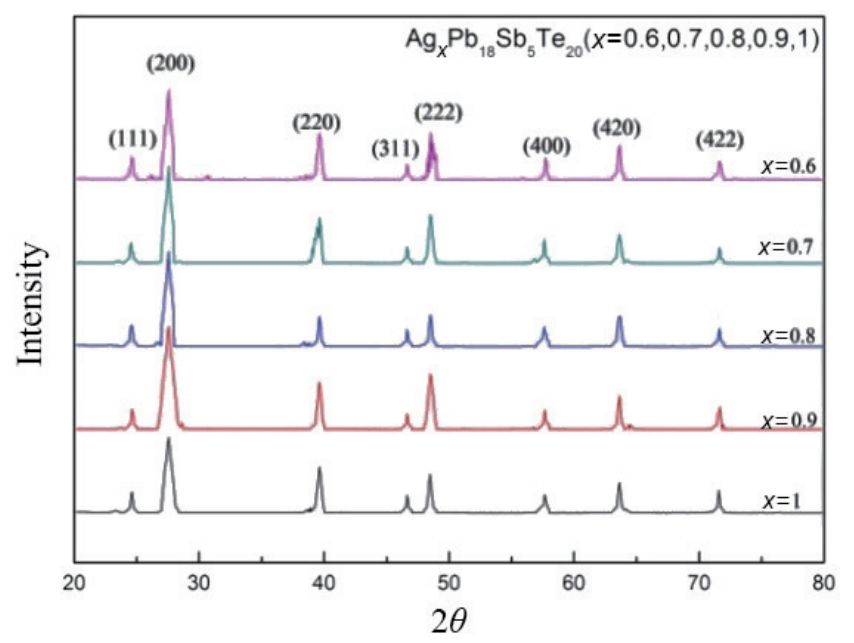

Fig. 1. (Color online) XRD plots of $\mathrm{Ag}_{x} \mathrm{~Pb}_{18} \mathrm{Sb}_{5} \mathrm{Te}_{20}(x=0.6,0.7,0.8,0.9,1)$.

\subsection{Structural analysis of fracture surface}

Figure 2(a) shows an image of the fracture surface of $\mathrm{Pb}_{18} \mathrm{Sb}_{5} \mathrm{Te}_{20}(1000 \times)$ without the addition of Ag. It can be seen from Figs. 2(b)-2(e) that there are clear white stripes on the surface, which result from the precipitation of $\mathrm{Sb}^{3+}$ and $\mathrm{Pb}^{2+}$. This precipitation causes distortion of the lattice structure. This observation is consistent with Ref. 1, in which doping PbTe with $\mathrm{Ag}$ and $\mathrm{Sb}$ caused similar clear stripes to appear. These structural and resulting electronic changes cause local deformation which has a large influence on material properties. As the amount of Ag is increased so do the number of white stripes, which eventually become patches that also increase in number.

\subsection{Seebeck coefficient of $\mathrm{Ag}_{x} \mathrm{~Pb}_{18} \mathrm{Sb}_{5} \mathrm{Te}_{20}(x=0.6,0.7,0.8,0.9,1)$ and temperature}

Figure 3 shows plots of the Seebeck coefficient of $\mathrm{Ag}_{x} \mathrm{~Pb}_{18} \mathrm{Sb}_{5} \mathrm{Te}_{20}(x=0.6,0.7,0.8,0.9,1)$ as a function of temperature. An increase in the amount of Ag improves the value of the Seebeck coefficient. When the temperature reaches $418 \mathrm{~K}$, the Seebeck coefficient reaches a maximum of $-315.21 \mu \mathrm{V} / \mathrm{K}$. The Seebeck coefficient is negative because the material is an $\mathrm{N}$-type semiconductor.

\subsection{Resistivity of $\mathrm{Ag}_{x} \mathrm{~Pb}_{18} \mathrm{Sb}_{5} \mathrm{Te}_{20}(x=0.6,0.7,0.8,0.9,1)$ and temperature}

Figure 4 shows the resistivity of $\mathrm{Ag}_{x} \mathrm{~Pb}_{18} \mathrm{Sb}_{5} \mathrm{Te}_{20}(x=0.6,0.7,0.8,0.9,1)$ as a function of temperature. It can be seen that resistivity decreases as the temperature rises. At $518 \mathrm{~K}$, the resistivity of $\mathrm{Ag}_{0.6} \mathrm{~Pb}_{18} \mathrm{Sb}_{5} \mathrm{Te}_{20}$ reaches a minimum value of $3 \times 10^{-6} \Omega$-m and an increase in the amount of $\mathrm{Ag}$ does not raise the resistivity. When the temperature rises above $400 \mathrm{~K}$, the decrement of resistivity becomes small. A previous study ${ }^{(18)}$ showed that the semiconductor properties of $\mathrm{PbTe}$ decrease with a rise in temperature. We presume that the semiconductor properties result from the added Ag which alters the Fermi energy density of PbSbTe. 


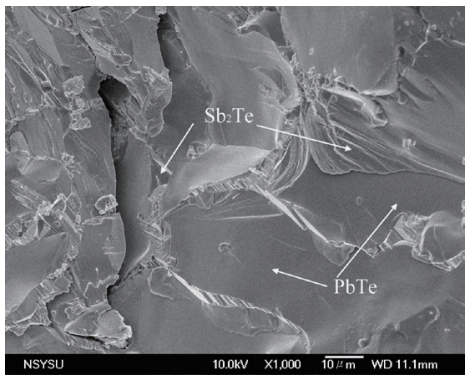

(a)

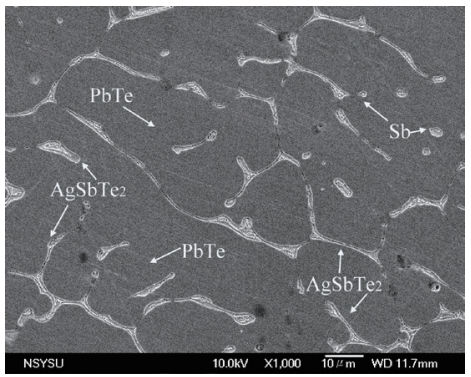

(d)

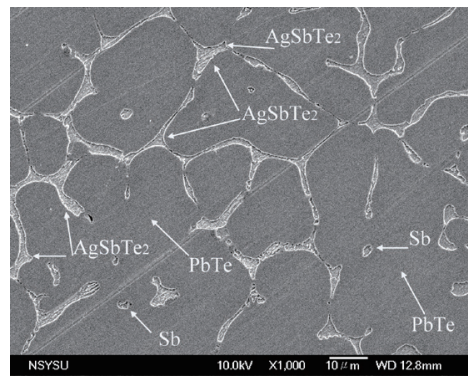

(b)

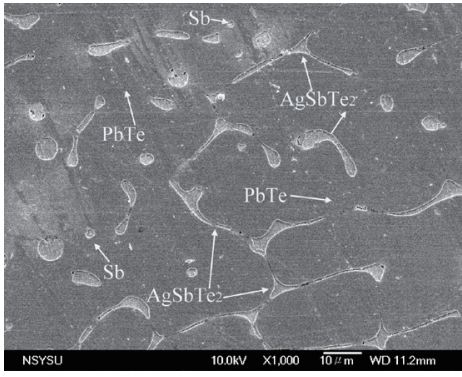

(e)

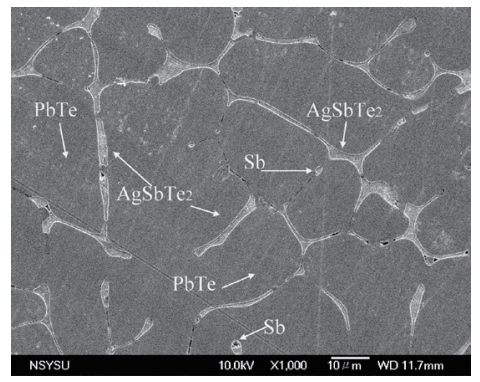

(c)

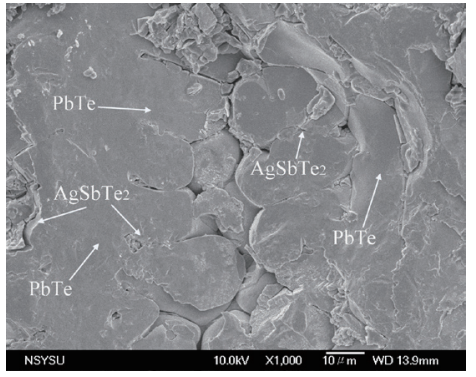

(f)

Fig. 2. SEM images of fracture surfaces of (a) $\mathrm{Pb}_{18} \mathrm{Sb}_{5} \mathrm{Te}_{20}$, (b) $\mathrm{Ag}_{0.6} \mathrm{~Pb}_{18} \mathrm{Sb}_{5} \mathrm{Te}_{20}$, (c) $\mathrm{Ag}_{0.7} \mathrm{~Pb}_{18} \mathrm{Sb}_{5} \mathrm{Te}_{20}$, (d) $\mathrm{Ag}_{0.8} \mathrm{~Pb}_{18} \mathrm{Sb}_{5} \mathrm{Te}_{20}$, (e) $\mathrm{Ag}_{0.9} \mathrm{~Pb}_{18} \mathrm{Sb}_{5} \mathrm{Te}_{20}$, and (f) $\mathrm{Ag}_{1} \mathrm{~Pb}_{18} \mathrm{Sb}_{5} \mathrm{Te}_{20}$.

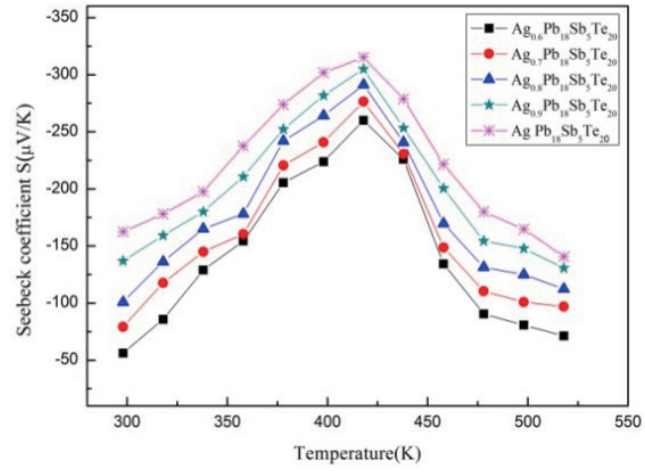

Fig. 3. (Color online) Plots of Seebeck coefficient of $\mathrm{Ag}_{x} \mathrm{~Pb}_{18} \mathrm{Sb}_{5} \mathrm{Te}_{20}(x=0.6,0.7,0.8,0.9,1)$ as a function of temperature.

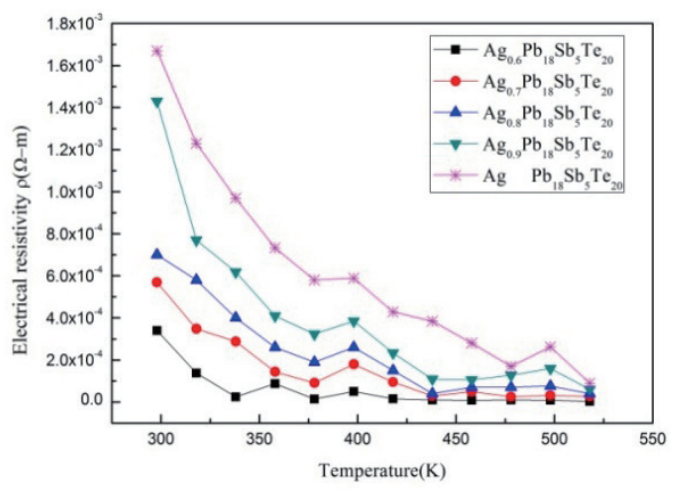

Fig. 4. (Color online) Resistivity of $\mathrm{Ag}_{x} \mathrm{~Pb}_{18} \mathrm{Sb}_{5} \mathrm{Te}_{20}(x$ $=0.6,0.7,0.8,0.9,1)$ as a function of temperature.

\subsection{Power factor of $\mathrm{Ag}_{x} \mathrm{~Pb}_{18} \mathrm{Sb}_{5} \mathrm{Te}_{20}(x=0.6,0.7,0.8,0.9,1)$ and temperature}

Figure 5 shows the power factor of $\mathrm{Ag}_{x} \mathrm{~Pb}_{18} \mathrm{Sb}_{5} \mathrm{Te}_{20}(x=0.6,0.7,0.8,0.9,1)$ as a function of temperature. The power factor is calculated from the relationship between the Seebeck coefficient and resistivity. It can be seen that the power factor increases or decreases with temperatures below or above $438 \mathrm{~K}$, respectively. This is consistent with earlier findings. ${ }^{(19)}$ The maximum power factor of $\mathrm{Ag}_{0.6} \mathrm{~Pb}_{18} \mathrm{Sb}_{5} \mathrm{Te}_{20}$ of $2.02 \times 10^{-4} \mathrm{~W} / \mathrm{mK}^{2}$ is observed at $438 \mathrm{~K}$ because of the significant decrease in both resistivity and the Seebeck coefficient. 


\subsection{Thermal conductivity of $\mathrm{Ag}_{x} \mathrm{~Pb}_{18} \mathrm{Sb}_{5} \mathrm{Te}_{20}(x=0.6,0.7,0.8,0.9,1)$ and temperature}

Figure 6 shows the thermal conductivity of $\mathrm{Ag}_{x} \mathrm{~Pb}_{18} \mathrm{Sb}_{5} \mathrm{Te}_{20}(x=0.6,0.7,0.8,0.9,1)$ as a function of temperature. It can be seen that, as the temperature rises, the thermal conductivity decreases. At $298 \mathrm{~K}$, a value of $8.96 \mathrm{~W} / \mathrm{mk}$ is observed, which is higher than that of $2.3 \mathrm{~W} / \mathrm{mk}$ for PbTe produced by normal pressure sintering. ${ }^{(20)}$ High thermal conductivity is associated with two related factors: the thermal conductivity of electrons $\kappa_{\mathrm{e}}$ of $\mathrm{Pb}_{0.55} \mathrm{Te}_{0.45},{ }^{(21)}$ and the thermal conductivity of the crystal phonon $\kappa_{\mathrm{ph}} . \kappa_{\mathrm{e}}$ can be calculated using the Wiedemann-Franz law, $\kappa_{\mathrm{e}}=L \sigma T$, where $L$ is the Lorenz number $\left(L=2.45 \times 10^{-8} \mathrm{~W} \Omega \mathrm{K}^{-2}\right)$ and $T$ is the absolute temperature. When $\kappa=\kappa_{\mathrm{e}}+\kappa_{\mathrm{ph}}$, we can obtain $\kappa_{\mathrm{ph}} . \mathrm{Ag}_{x} \mathrm{~Pb}_{18} \mathrm{Sb}_{5} \mathrm{Te}_{20}(x=0.6,0.7,0.8,0.9,1)$ has low resistivity that results in relatively high $\kappa_{\mathrm{e}}$.

\subsection{ZT value of $\mathrm{Ag}_{x} \mathrm{~Pb}_{18} \mathrm{Sb}_{5} \mathrm{Te}_{20}(x=0.6,0.7,0.8,0.9,1)$ and temperature}

Figure 7 shows the $\mathrm{ZT}$ value of $\mathrm{Ag}_{x} \mathrm{~Pb}_{18} \mathrm{Sb}_{5} \mathrm{Te}_{20}(x=0.6,0.7,0.8,0.9,1)$ as a function of temperature. The maximum $\mathrm{ZT}$ value of 0.3 is observed at $438 \mathrm{~K}$. However, commercial $\mathrm{PbTe}$ has a ZT value of 1 and needs to be improved. We found that $\mathrm{Ag}_{0.6} \mathrm{~Pb}_{18} \mathrm{Sb}_{5} \mathrm{Te}_{20}$ had better thermoelectric

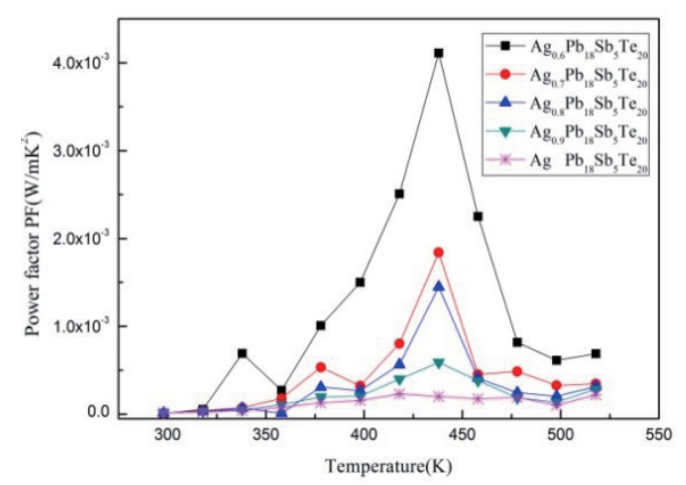

Fig. 5. (Color online) Power factor of $\mathrm{Ag}_{x} \mathrm{~Pb}_{18} \mathrm{Sb}_{5} \mathrm{Te}_{20}(x=0.6,0.7,0.8,0.9,1)$ as a function of temperature.

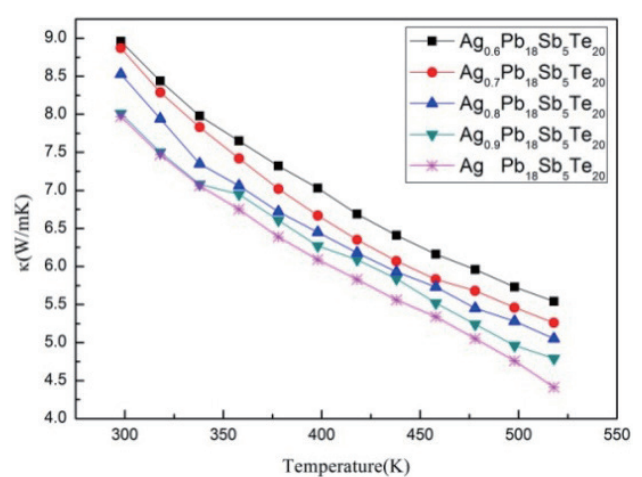

Fig. 6. (Color online) Thermal conductivity of $\mathrm{Ag}_{x} \mathrm{~Pb}_{18} \mathrm{Sb}_{5} \mathrm{Te}_{20}(x=0.6,0.7,0.8,0.9,1)$ as a function of temperature.

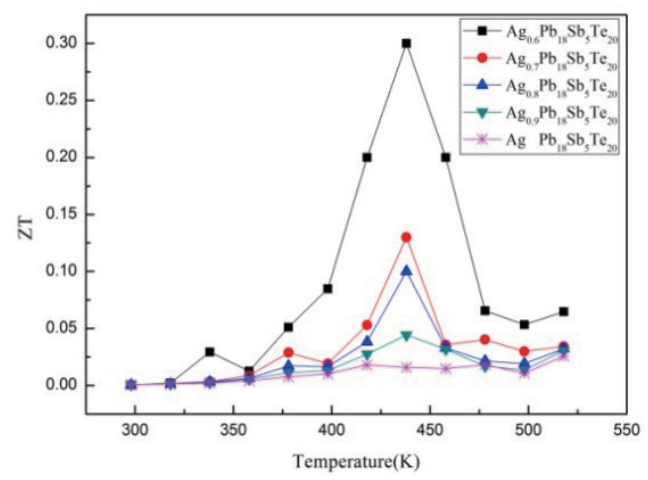

Fig. 7. (Color online) $\mathrm{ZT}$ value of $\mathrm{Ag}_{x} \mathrm{~Pb}_{18} \mathrm{Sb}_{5} \mathrm{Te}_{20}(x$ $=0.6,0.7,0.8,0.9,1)$ as a function of temperature. 
properties. Therefore, $\mathrm{Ag}_{x} \mathrm{~Pb}_{18} \mathrm{Sb}_{5} \mathrm{Te}_{20}$ should be annealed to see if this would improve its thermoelectric properties.

\section{Conclusions}

A vacuum arc furnace was used to fabricate bulk $\mathrm{Pb}_{18} \mathrm{Sb}_{5} \mathrm{Te}_{20}$ doped with $\mathrm{Ag}$ to form $\mathrm{Ag}_{x} \mathrm{~Pb}_{18} \mathrm{Sb}_{5} \mathrm{Te}_{20}(x=0.6,0.7,0.8,0.9,1)$ ternary alloys. The composition, microstructure, and thermoelectric properties of the alloy were analyzed.

1. Analysis of compositions and microstructure

The XRD measurement of $\mathrm{Ag}_{x} \mathrm{~Pb}_{18} \mathrm{Sb}_{5} \mathrm{Te}_{20}(x=0.6,0.7,0.8,0.9,1)$ alloys shows the crystal structure to be FCC and hexagonal close-packed (HCP). The SEM images show obvious stripes on the fracture surfaces which may be related to the $\mathrm{PbTe}$ and $\mathrm{Sb}_{2} \mathrm{Te}_{3}$ formed by precipitation of $\mathrm{Sb}^{3+}$ and $\mathrm{Pb}^{2+}$, despite this not being obvious in the $\mathrm{Ag}_{x} \mathrm{~Pb}_{18} \mathrm{Sb}_{5} \mathrm{Te}_{20}(x=0.6,0.7,0.8,0.9,1)$ case.

2. Analysis of thermoelectric properties

The resistivity of $\mathrm{Ag}_{x} \mathrm{~Pb}_{18} \mathrm{Sb}_{5} \mathrm{Te}_{20}(x=0.6,0.7,0.8,0.9,1)$ decreases as the temperature increases. Among the alloys, $\mathrm{Ag}_{x} \mathrm{~Pb}_{18} \mathrm{Sb}_{5} \mathrm{Te}_{20}$ has the highest resistivity of $1.67 \times 10^{-3} \Omega-\mathrm{m}$ at $298 \mathrm{~K}$. However, an increase in the amount of $\mathrm{Ag}$ does not decrease resistivity. It is likely that the addition of $\mathrm{Ag}$ alters the crystal structure.

The thermal conductivity of $\mathrm{Ag}_{x} \mathrm{~Pb}_{18} \mathrm{Sb}_{5} \mathrm{Te}_{20}(x=0.6,0.7,0.8,0.9,1)$ ternary alloys decreases with increasing temperature, and $\mathrm{Ag}_{x} \mathrm{~Pb}_{18} \mathrm{Sb}_{5} \mathrm{Te}_{20}$ has a thermal conductivity of $4.41 \mathrm{~W} / \mathrm{mk}$ at $518 \mathrm{~K}$ as expected.

An analysis of $\mathrm{ZT}$ values shows that $\mathrm{Ag}_{0.6} \mathrm{~Pb}_{18} \mathrm{Sb}_{5} \mathrm{Te}_{20}$ has the highest $\mathrm{ZT}$ value of 0.3 at 438 $\mathrm{K}$. Since commercial PbTe has a ZT value of 1 , further improvement is needed. Annealing was not carried out in this experiment and this might have affected the ZT values. In the future we will anneal the alloys to see if this improves their ZT values.

\section{Acknowledgements}

The author gratefully acknowledges the financial support provided for this study by the National Science Council (NSC) of Taiwan under contract no. NSC 102-2212-E-151-006-MY3.

\section{References}

1 T. M. Tritt, H. Bottner, and L. D. Chen: MRS Bull. 33 (2008) 366.

2 G. J. Snyder and E. S. Toberer: Nat. Mater. 7 (2008) 105.

3 G. S. Nolas, J. Sharp, and H. J. Goldsmid: Thermoelectrics-basic principles and new materials developments, (Springer, New York, 2001) pp. 2-5.

4 T. J. Zhu, F. Yan, X. B. Zhao, S. N. Zhang, Y. Chen, and S. H. Yang: J. Phys. D-Appl. Phys. 40 (2007) 6094.

5 T. Ikeda, V. A. Ravi, and G. J. Snyder: Acta Mater. 57 (2009) 666.

6 H. J. Wu, S. W. Chen, T. Ikeda, and G. J. Snyder: Acta Mater. 60 (2012) 6144.

7 C. H. Kuo, C. S. Hwang, M. S. Jeng, W. S. Su, Y. W. Choua, and J. R. Ku: J. Alloy Compd. 496 (2010) 687.

8 D. Li, R.R. Sun and X.Y. Qin: Intermetallics 19 (2011) 2002.

9 K. F. Hsu, S. Loo, F. Guo, W. Chen, J. S. Dyck, C. Uher, T. Hogan, E. K. Polychroniadis, and M. G. Kanatzidis: Science 303 (2004) 818

10 Z. H. Dughaish: Physica B 322 (2002) 205

11 Z. Y. Li, M. Zou, and J. F. Li: J. Alloy Compd. 549 (2013) 319

12 J. H. Yang and T. Caillat: MRS Bull. 31 (2006) 224. 
13 A. Kosuga, M. Uno, K. Kurosaki, and S. Yamanaka: J. Alloy. Compd. 391 (2005) 288.

14 H. S. Dow, M. W. Oh, S. D. Park, B. S. Kim, B. K. Min, H. W. Lee, and D. M. Wee: J. Appl. Phys. 105 (2009) 1137031.

15 H. Wang, J. F. Li, C. W. Nan, M. Zhou, W. S. Liu, B. P. Zhang, and T. Kita: Appl. Phys. Lett. 88 (2006) 0921041

16 H. Li, K. F. Cai, Y. Du, H. F. Wang, S. Z. Shen, X. L. Li, Y. Y. Wang, and C. W. Zhou: Curr. Appl. Phys. 12 (2012) 188

17 Y. Zhou, X. Lin, S. Bai, and L. Chen: J. Cryst. Growth 312 (2010) 775

18 T. Su, X. Jia, H. Ma, and F. Yu: J. Appl. Phys. 105 (2009) 073713

19 H. Li, K. F. Cai, H. F. Wang, L. Wang, J. L.Yin, and C. W. Zhou: J. Solid State Chem. 182 (2009)869.

20 S. Maneewan, J. Hirunlabh, J. Khedari, B. Zeghmati, and S. Teekasap: Solar Energy 78 (2005) 495.

21 T. Su, X. Jia, H. Ma, J. Guo, Y. Jiang, N. Dong, L. Deng, X. Zhao, T. Zhu, and C. Wei: J. Alloys Compd. 468 (2009) 410. 